\title{
Taxation of nuclear rents: Benefits, drawbacks, and alternatives
}

\author{
J. Morbee ${ }^{*, 1}$, P. Himpens ${ }^{1}$, S. Proost ${ }^{1}$ \\ Center for Economic Studies (Department of Economics), KU Leuven Energy Institute, KU Leuven, Naamsestraat 69, BE-3000 Leuven, Belgium
}

\section{A R T I C L E I N F O}

\section{Article history:}

Received 26 August 2011

Received in revised form 25 May 2015

Accepted 10 June 2015

Available online 19 June 2015

\section{JEL classification:}

H25

L12

Q41

Q48

\section{Keywords:}

Electricity market

Nuclear rent

Taxation

Lifetime extension

Investment

\begin{abstract}
A B S T R A C T
This paper studies the taxation of nuclear energy using a stylized model of the electricity sector, with one dominant nuclear producer and a competitive fringe of non-nuclear plants. First, we find that the optimal nuclear tax is different depending on the time horizon: the optimal short-run tax has the same order of magnitude as the nuclear taxes imposed in Belgium and Germany, while in the long run the optimal tax may be negative, i.e. a subsidy. Second, government credibility is important: when a government cannot credibly commit, the mere possibility of a short-run tax could severely harm incentives for future investments in lifetime-extending refurbishment or new plants. Third, when there is natural scarcity in nuclear potential, other policies like inviting multiple competitive bidders for lifetime extension franchises or for investments in new plants, may be more efficient ways to increase government revenue.
\end{abstract}

(c) 2015 Elsevier B.V. All rights reserved.

\section{Introduction}

Towards the end of 2008, the government of Belgium attempted to reduce its budget deficit by imposing a tax of 250 million euros on nuclear power producers. Despite appeals to Belgium's Constitutional Court, the tax was upheld and repeated as an annual tax in 2009, 2010 and 2011. The tax burden was allocated to nuclear producers in proportion to their capacities, and amounted to around 5 EUR/MWh produced. Starting in 2012 the tax was more than doubled, to 550 million euros, i.e. roughly 11 EUR/MWh produced. In July 2014, the 2012 tax of 550 million euros was upheld by the Constitutional Court. ${ }^{2}$ Meanwhile in Germany, in the second half of 2010, the center-right government and the nuclear power producers agreed to extend the planned lifetime of Germany's nuclear power plants in return for a new fuel-rod tax and a compulsory contribution to a renewable energy fund, later to be

\footnotetext{
* Corresponding author.

E-mail addresses: research@jorismorbee.com (J. Morbee), pieterhimpens@gmail.com (P. Himpens), stef.proost@kuleuven.be (S. Proost).

1 The views expressed are purely those of the author and may not in any circumstances be regarded as stating an official position of the organization he is affiliated with.

2 It can be expected that the tax will be adjusted for 2014, given the outage of multiple nuclear reactors. Furthermore, in December 2014 the Belgian government decided to allow lifetime extension of two of the oldest nuclear reactors by 10 years, until 2025, subject to negotiations with the incumbent and approval by the nuclear control agency. The negotiations may obviously lead to a change in taxation.
}

replaced by a renewables levy per MWh produced. The total resulting charge to the nuclear producers in Germany amounted to slightly over $15 \mathrm{EUR} / \mathrm{MWh}{ }^{3,4}$

In this paper we study the taxation of nuclear rents, using six scenarios. First we analyze the potential of a short-run 'unexpected' tax on nuclear production (scenario 1), as in the case of Belgium. Next, we study the potential of long-run (scenario 2 ) or medium-run (scenario 3) nuclear taxes, taking into account the possible need for investments in new nuclear plants or in lifetime extensions. Scenario 3 is representative for the situation in Germany in 2010. Subsequently, the effect of lack of government commitment is studied through two additional scenarios: one with commitment to a tax that is too high (scenario 4) and one with complete government unreliability (scenario 5). Finally, in our analysis of policy options, we discuss other taxation instruments, and

\footnotetext{
${ }^{3}$ The information in this paragraph is obtained from articles in De Tijd (2010-2014), Financial Times (2011) and The Economist (2011). Note that as a result of the March 2011 Fukushima accident, however, the German government eventually annulled the lifetime extension and accelerated the nuclear phase-out. In the days after Fukushima, the German government ordered a temporary shutdown of the seven oldest nuclear reactors. Furthermore, the decision to extend the lifetime of nuclear power plants beyond 2022, which the government had taken in 2010, was overturned. In May 2011 the shutdown of the seven reactors was made permanent. The lifetime of the remaining 10 reactors is now limited to 2022.

${ }^{4}$ Note that our paper is focused on taxation of economic rents. The Fukushima accident has illustrated the external cost of nuclear power, which could be addressed separately through a Pigouvian tax. The latter is not the subject of this paper.
} 
Table 1

Overview of nuclear electricity generation capacity in Europe.

\begin{tabular}{|c|c|c|c|}
\hline \multirow[t]{2}{*}{ Country } & \multirow{2}{*}{$\begin{array}{l}\text { Nuclear capacity } \\
\text { (Dec. 31, 2010) } \\
\text { MW }\end{array}$} & \multirow{2}{*}{$\begin{array}{l}\text { Share of nuclear in total } \\
\text { gross electricity } \\
\text { generation (2008) } \\
\%\end{array}$} & \multirow{2}{*}{$\begin{array}{l}\text { Share of nuclear } \\
\text { capacity owned } \\
\text { by largest } 2 \text { players } \\
\text { (Dec. } 31,2010 \text { ) } \\
\%\end{array}$} \\
\hline & & & \\
\hline France & 62950 & $76 \%$ & $99.7 \%$ \\
\hline Germany & 19895 & $23 \%$ & $50.1 \%$ \\
\hline Sweden & 9248 & $43 \%$ & $75.0 \%$ \\
\hline United Kingdom & 9218 & $13 \%$ & $100.0 \%$ \\
\hline Spain & 7409 & $19 \%$ & $61.2 \%$ \\
\hline Belgium & 5839 & $54 \%$ & $97.3 \%$ \\
\hline Czech Republic & 3775 & $32 \%$ & $100.0 \%$ \\
\hline Switzerland & 3220 & $40 \%$ & $66.3 \%$ \\
\hline Finland & 2721 & $30 \%$ & $100.0 \%$ \\
\hline Hungary & 1946 & $37 \%$ & $100.0 \%$ \\
\hline Slovakia & 1940 & $58 \%$ & $100.0 \%$ \\
\hline Bulgaria & 1906 & $35 \%$ & $100.0 \%$ \\
\hline Romania & 1310 & $17 \%$ & $100.0 \%$ \\
\hline Slovenia & 664 & $38 \%$ & $100.0 \%$ \\
\hline Netherlands & 479 & $4 \%$ & $100.0 \%$ \\
\hline
\end{tabular}

Source: Platts (2010), Eurostat (2011).

apply the same model setting to auctions of licenses for new capacity or for lifetime extension (scenario 6).

The economic model developed in this paper is applicable to various countries. Table 1 provides an overview of European countries that have nuclear energy in their generation mix. The table also shows that nuclear firms often have large, concentrated market shares and may therefore be able to exercise market power on national or regional electricity markets. This is an important feature of the nuclear sector, which we will explicitly include in this paper using a 'dominant firm-competitive fringe' model.

The paper is structured as follows. Section 2 reviews the literature. Section 3 develops our analytical model of an electricity market with a significant share of nuclear production, and identifies the different components of nuclear rents. Section 4 investigates the potential magnitude and impact of a nuclear tax on a monopolist bounded by a capacity constraint. Next, Section 5 demonstrates the effects of lack of commitment of governments to tax rates, on investment decisions. Section 6 studies alternative policy measures. Section 7 illustrates the results numerically for the case of Belgium. Section 8 concludes the paper.

\section{Literature review}

The issue of nuclear rents has been studied from a policy perspective by e.g. CREG (2010a), in which the nuclear cost structure and rent are estimated for Belgium; CREG (2010b), which compares the German and Belgian taxation policies; and Matthes (2010), which estimates nuclear power plant lifetime extension costs for Germany. Our paper aims to complement these case studies by developing a formal model that allows for graphical and analytical demonstration of the underlying economic principles.

The oligopolistic nature of our model embodies a number of issues studied in the vast literature on electricity market deregulation, such as the analysis by Newbery (2002) of the effectiveness of the deregulation process and the accompanying problems. Indeed, the ongoing policy challenges regarding taxation of nuclear rents are a consequence of the liberalization of formerly regulated electricity monopolies. Our paper fits into the broader literature on optimal regulation of oligopolies and the electricity sector in particular. Well-known literature such as Demsetz (1968) and Stigler (1971) questions the benefits of such regulation for society as a whole, as opposed to the special interest group of the electricity companies. Models that do advocate regulation of monopolies, typically show that the first-best solution in the case of a technology with low marginal costs-such as nuclear power-is to subsidize the monopolist in order to allow them to set prices at marginal cost without going out of business: both Train (1991) and Romano (1988) argue that the optimal production subsidy to an unconstrained monopolist is positive for each marginal unit above the unsubsidized monopolist's output. The same principle is valid in the 'dominant firm-competitive fringe' model used in this paper: we will find that the optimal tax rate of nuclear power in the long run may be negative. One of the key differences is that in our model there is a severe capacity constraint on nuclear production, which is especially relevant in the short run. The first-best solution is then to charge the price that reduces demand to the level of available capacity. Riordan (1984) proposes a subsidy scheme to create incentives for correct pricing. However, in the current case, this would result in a negative subsidy, i.e. a lump sum tax on the nuclear firm, which may be difficult to realize for legal reasons.

The government's ability and incentives to introduce ex-post taxes on nuclear production in the short run may hamper investments in new capacity because firms may fear expropriation of profits. This is a well-known problem in the tax competition literature. Janeba (2000) uses a model in which one firm produces for the world market and its profits are taxed by the government. When the production has to be local, there is a standard time inconsistency problem. The government has an interest to raise the tax after the investment, the firm understands this ex ante and the firm would never invest. In Janeba's model this problem can be avoided by the firm at a high cost by building extra capacity in another country and shifting production to the country where the net profit is the highest. According to Janeba (2000), when capacity costs are sufficiently low, this is the equilibrium. For higher capacity costs, there is an equilibrium without investment. In our case, even if there were enough international transmission capacity, high nuclear capacity costs would rule out an equilibrium with excess capacities. An alternative way to avoid the time inconsistency problem is to rely on other constraints on the behavior of governments. One legal option is to have constitutions that rule out governments changing the tax rules. This type of rule exists in order to limit government debt but is rather naive as governments have by definition the power to tax profits more and lower other taxes. A second constraint could be reputation, but behavioral models of government (see e.g. Besley, 2006) and evidence from countries such as Germany and Belgium, show that governments have incentives to overrule reputation concerns. A dedicated section of our paper will analyze the implications of lack of credible commitment.

Our paper is related to a paper by Fridolfsson and Tangerås (2011), who study nuclear capacity auctions. They first argue that nuclear power deserves a specific policy treatment due to entry barriers, such as site ownership by incumbents, and the large investments required. Then, they make specific recommendations for nuclear capacity auctions, such as maximizing the number of participants, including incumbents (but not together in one consortium) and industrial consumers, and stimulating the sale of virtual power plants and/or long-term supply contracts. Our paper is not so much focused on auction design for new investments, but rather on an analysis of the various ways in which a government can capture part of the nuclear rent via excise-type of taxes. Looking beyond simple taxation instruments, the analysis in this paper will find that lifetime extension agreements negotiated with multiple potential players, and competitive auctioning of new nuclear licenses are the most attractive policies. The bargaining and auctioning aspect is stylized, in order to permit transparent comparison with the outcomes of simple taxation. A more elaborate treatment of nuclear capacity auctions is provided by Fridolfsson and Tangerås (2011).

In the next section we explain the different elements of our analytical model. 


\section{Model set-up}

\subsection{Demand and supply}

We study a stationary electricity market with linear demand:

$q(p)=q_{0}-\beta p$

with constant parameters $q_{0}$ and $\beta$. We assume normal downward sloping demand, hence $\beta \geq 0$. To focus our thoughts, we assume that this is the electricity market of one single country. The demand $q(p)$ represents an 'average' demand in the course of a year, and we do not consider any demand variations within the year, or even within the days of the year. ${ }^{5}$

Two supply technologies are available: (i) nuclear generation with marginal production cost $M C_{n}=c_{n}$, and (ii) fossil-fuel-based generation with linearly increasing marginal production costs $c_{0}+\alpha q$. Because of the low marginal production costs of nuclear power, we assume $c_{n}<c_{0}$. Nuclear generation $q_{n}$ is limited by the installed nuclear capacity: $q_{n \text { max }}$. We assume that this is also the maximum amount of nuclear power that can be installed. This may be due to various reasons: technical (e.g. limited access to cooling, insufficient ability of nuclear power to cope with demand variability), political, ethical, etc. The cost curve $c_{0}+\alpha q$ aggregates different fossil-fuel power plants and also includes any relevant foreign production capacity that can be imported. Additional transmission costs for foreign production are included in $c_{0}+\alpha q$. We assume that the competitive fringe cost curve is stable over time: the marginal cost differences among the competitive fringe suppliers continue to exist because the stochastic nature of electricity demand requires a mix of technologies with different cost characteristics.

\subsection{Equilibrium concept}

We consider a 'dominant firm-competitive fringe' game, which is fairly standard in microeconomic analysis. ${ }^{6}$ We assume that all nuclear production capacity is controlled by one 'dominant firm'. Considering the strong concentration in nuclear power as shown in Table 1, this assumption is not unrealistic, and serves as a 'worst case' baseline for the cases with more than one producer. The fossil-fuel and foreign capacity represented by $c_{0}+\alpha q$ is assumed to be operated by a 'competitive fringe'. In this model, the dominant firm behaves strategically, while the competitive fringe always produces up to the point where price equals marginal cost.

Fig. 1 illustrates our equilibrium concept. The thick black line is the industry marginal cost curve. Under perfect competition, the market equilibrium would be at point $A$, the intersection of the industry marginal cost curve and the demand curve. Since it is in practice technically impossible to serve an entire electricity system with nuclear power, we assume that the intersection of supply and demand is always in the upward sloping part of the supply curve (i.e. the part provided by the

\footnotetext{
${ }^{5}$ Even with variability of $q_{0}$, the average equilibrium price corresponds to the price computed by our stationary model for the average value of $q_{0}$. Indeed, as we will see below, supply and demand are assumed to always intersect in the same linear part of the supply curve, hence the equilibrium price $p_{0}^{*}$ can be written as a linear function $f(\cdot)$ of $q_{0}$ (see Eq. (2)), which proves the point. To illustrate this, suppose $q_{0}$ is replaced by a stochastic variable $\mathbf{q}_{0}$ with mean $\bar{q}_{0}$. Then the expected value $\bar{p}_{0}^{*}$ of the corresponding stochastic price variable $\mathbf{p}_{\mathbf{0}}^{*}$ would be $\bar{p}_{0}^{*}=E\left[\mathbf{p}_{0}^{*}\right]=E\left[f\left(\mathbf{q}_{\mathbf{0}}\right)\right]=f\left(E\left[\mathbf{q}_{\mathbf{0}}\right]\right)=f\left(\bar{q}_{0}\right)$, in which the penultimate step follows from the linearity of $f(\cdot)$. Hence, conclusions about average equilibrium price $p_{0}^{*}$ will be valid, even with variations in demand. However, this does not carry over to profits-and hence, firms' incentives-since profit is a quadratic function of quantity. Furthermore, it does not apply to variations in $\beta$ either, since $\beta$ has a non-linear effect on prices and quantities.

${ }^{6}$ See e.g. Carlton and Perloff (2000).
}

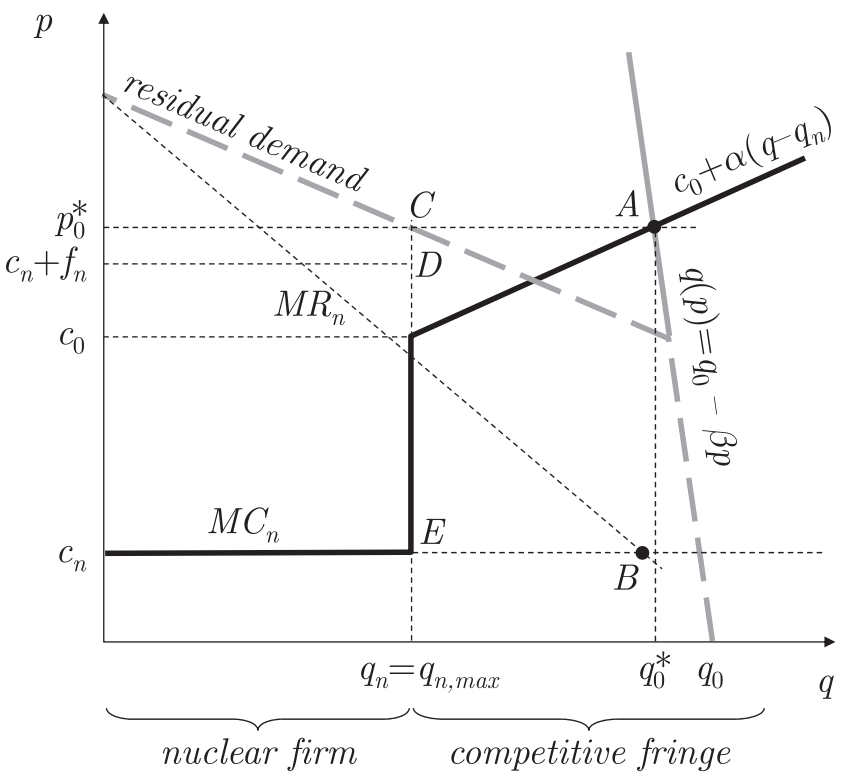

Fig. 1. Equilibrium in the 'dominant firm-competitive fringe' game described in this paper.

competitive fringe). The equilibrium price and quantity under perfect competition are $p_{0}^{*}$ and $q_{0}^{*}$ :

$p_{0}^{*}=\frac{c_{0}+\alpha\left(q_{0}-q_{n, \max }\right)}{1+\alpha \beta}$

$q_{0}^{*}=\frac{q_{0}-\beta\left(c_{0}-\alpha q_{n, \max }\right)}{1+\alpha \beta}$

In our 'dominant firm-competitive fringe' model, however, the equilibrium can be determined by considering the residual demand curve (i.e. demand minus the quantities supplied by the competitive fringe) and analyzing the dominant firm as a monopolist on this residual demand curve. As shown in Fig. 1, the residual demand curve translates into a marginal revenue curve $\left(M R_{n}\right)$ of the dominant firm. If nuclear capacity was not constrained by $q_{n, \max }$ then the 'dominant firmcompetitive fringe' equilibrium in this monopoly game would be at point $B$, i.e. the intersection of $M R_{n}$ and the dominant firm's (constant) marginal cost curve. However, given the nuclear capacity constraint $\left(q_{n} \leq q_{n, \max }\right)$, the dominant firm's quantity decision $q_{n}$ becomes equal to $q_{n, \max }$. As a result, the equilibrium prices and quantities are the same as under perfect competition, at least in the case shown in Fig. 1. Only with high operating costs and large capacity would the dominant nuclear have an interest in exploiting his market power by not fully using the available capacity. However, due to the relatively low marginal cost of nuclear production, the constraint $q_{n} \leq q_{n \text {,max }}$ is generally binding. As a result, in this model, even a single dominant nuclear firm typically does not have an incentive to withhold production. ${ }^{7}$ In order to keep our argument focused, we will assume that-in the absence of taxes on nuclear production-the constraint $q_{n} \leq q_{n \text {,max }}$ is indeed binding, at least in the short run.

\footnotetext{
${ }^{7}$ Note that it may be the case that the dominant nuclear firm is also owner of some of the competitive fringe capacity. We do not consider any withholding of such fringe capacity owned by the dominant firm. The purpose of this paper is to study taxes on nuclear production; any strategic use of fringe capacity is a separate issue that is not directly affected by taxes on nuclear production.
} 
This assumption can be expressed mathematically. From Eq. (1) and the cost curve of the competitive fringe, we can easily derive the inverse residual demand curve $p_{R}(q)$, and subsequently $M R_{n}$ :

$p_{R}(q)=\frac{c_{0}+\alpha\left(q_{0}-q\right)}{1+\alpha \beta}$

$M R_{n}=\frac{c_{0}+\alpha\left(q_{0}-2 q\right)}{1+\alpha \beta}$

In the absence of the constraint $q_{n} \leq q_{n, \max }$, the nuclear firm's unconstrained production quantity $q_{n, u n c o n}$ can be computed by setting $M R_{n}=M C_{n}=c_{n}$ :

$q_{n, \text { uncon }}=\frac{1}{2}\left(q_{0}+\frac{c_{0}-c_{n}}{\alpha}-\beta c_{n}\right)$

The constraint $q_{n} \leq q_{n, \max }$ will be binding if $q_{n} \leq q_{n, \text { uncon }}$. The latter condition can be expressed as:

$2 q_{n, \max } \leq q_{0}+\frac{c_{0}-c_{n}}{\alpha}-\beta c_{n}$

With the calibration parameters in Section 7, condition (7) is satisfied for Belgium, and it would remain satisfied even if Belgium's share of nuclear power were to increase to $69 \%$.

Our monopolistic 'dominant firm-competitive fringe' equilibrium concept and its oligopolistic extensions are more similar to the typical Cournot models than to the more sophisticated Supply Function Equilibria (SFE). The advantage of the former is clearly computational convenience, as acknowledged by e.g. Ventosa et al. (2005), Borenstein et al. (1999), Hobbs and Pang (2007) and Wei and Smeers (1999). Willems et al. (2009) confront Cournot models and SFE with data of the German electricity market. The authors conclude that SFE models do not significantly outperform the Cournot approach when studying the German electricity market but that they rely on fewer calibration parameters and may therefore be more robust. Willems et al. (2009) suggest that Cournot models are “...aptly suited for the study of market rules...", while SFE are suited to study e.g. long-term effects of mergers. In our setting, the Cournot-style approach seems therefore justified.

\subsection{Rents}

Fig. 1 demonstrates that nuclear producers obtain a rent $\left(p_{0}^{*}-c_{n}\right) q_{n}$. Three types of rent can be distinguished.

First, a large part is the perfectly competitive inframarginal rent required to cover the fixed costs (mostly investment costs) incurred by the nuclear firm. Indeed, while short-run marginal production costs are relatively low, the upfront capital investment of nuclear power is comparatively high. The discounted sum of inframarginal rents needs to cover that investment cost in order to provide sufficient investment incentives. We assume that the annuity of investment costs plus any relevant fixed operating costs is an amount $f_{n}$ per unit of capacity, hence a total cost of $f_{n} q_{n \text {,max }}$. The inframarginal rent is visible in Fig. 1 as the rectangle between the points $D, E$, and $c_{n}$ and $c_{n}+f_{n}$ on the vertical axis.

Secondly, there may be a scarcity rent. Indeed, without the constraint $q_{n \text {,max }}$, the long-run equilibrium installed capacity of nuclear power would evolve such that the electricity price equals $f_{n}+c_{n}$. As a result of the constraint, the nuclear firm in Fig. 1 obtains a scarcity rent $\left(p_{0}^{*}-c_{n}-f_{n}\right) q_{n}$, which is visible in Fig. 1 as the rectangle between the points $C, D$ and $c_{n}+f_{n}$ and $p_{0}^{*}$ on the vertical axis.

Thirdly, nuclear firms may obtain rents due to market power. In Fig. 1, no withholding takes place, hence there is no market power rent. As mentioned before, the low level of marginal costs makes withholding of nuclear capacity unlikely in general. However, as we will see below, there may be circumstances (e.g. in the event of nuclear taxation) that can lead to the long-run variety of withholding, namely underinvestment.

For the sake of simplicity, we will use the term 'nuclear rent'-or simply 'rent'-in the remainder of the paper. In the short run, this term comprises scarcity rent, inframarginal rent and any market power rent that arises due to taxation. In the medium and long run, this term comprises scarcity rent and any market power rent that arises due to taxation.

\subsection{Government}

In this paper, we study the policy options of the national government of the country under consideration. We assume that the government maximizes national welfare $W$ :

$W=C S+\sigma\left(\pi_{n}+\pi_{f}\right)+G$

with CS as the consumer surplus, $\pi_{n}$ as the profits of the nuclear firm, $\pi_{f}$ as the profits of the competitive fringe, $\sigma(0 \leq \sigma \leq 1)$ as the fraction of the power generation firms' shares owned by nationals of the country, and $G$ as the government revenues from the nuclear sector (taxes, licenses, etc.). Note that if, for ideological or other reasons, the government does not attach any importance to the income of the national shareholders of the power generation sector, this is equivalent to setting $\sigma=0$.

This paper studies how a government with objective function (8) taxes the scarcity rent. Hence, the focus of the paper is on the scarcity rent. Nevertheless, as mentioned in the introduction, governments may consider that the normal inframarginal rent should be zero in this case, since many nuclear power plants were built in an era of costplus regulation, and the bill has already been passed on to consumers. This would qualify the entire rent as scarcity rent and hence make it the object of taxation. Hence, for the analysis of the short run-which represents the case of current power plants-we will include the inframarginal rent as part of the rent targeted by the government, and evaluate the policies from that point of view.

Note however, that the trade-off between the interests of the economic entities in the objective function (8) does not always imply that the government would like to extract rents from producers, especially if $\sigma$ is close to 1 .

Finally, market power rent in this paper is only considered to the extent that it is impacted by the taxation of scarcity rent. To address market power itself, standard competition policy instruments can be applied, and taxation may not be the optimal approach.

\subsection{Short-run and long-run interpretation of the model}

We can give three different interpretations to our model.

(1) The short run, in which capacity is fixed and $c_{n}$ represents shortrun variable production costs. This situation was implictly assumed in the discussion above.

(2) The long run, in which capacity is not fixed (the firm needs to make an investment decision) and variable costs are hence higher since they include both the short-run variable costs and the capacity costs. This situation can also be analyzed using the model discussed above, by replacing $c_{n}$ with $c_{n}+f_{n}$.

(3) An intermediate situation, named the medium run, in which existing capacity can only be used when it is first refurbished, at a cost $f_{n}^{\prime}$ per unit of capacity, which is lower than the capacity costs $f_{n}$ for new capacity. The variable cost in this situation includes both the short-run variable cost and the refurbishment cost. Again, this situation can be analyzed using the model discussed above, by replacing $c_{n}$ with $c_{n}+f_{n}^{\prime}$. 


\section{Taxation of a monopolist with a capacity constraint}

In this section, we study to what extent the government would tax the nuclear firm in the market setting described above. As mentioned in the introduction this is essentially a question about taxation of a monopolist, for which the optimal policy according to standard theory is a subsidy. What makes the model in this paper different, is (i) the presence of a capacity constraint on nuclear energy, and (ii) the fact that the government may not be a perfect social planner if $\sigma<1$, i.e. if it has an objective function that attaches less weight to profits. Therefore we will see that in this model there are many situations in which it is optimal for the government to tax the nuclear firm.

We consider a tax of $\tau$ per unit of nuclear electricity produced. The optimal tax rate depends particularly on the level of variable costs considered. Therefore, this section explores the three different situations described in Section 3.5. All three situations can be analyzed using the model described in Section 3, by replacing the variable cost $c_{n}$ by the appropriate value. In this section we will first derive the optimal tax $\tilde{\tau}$ on a nuclear firm with marginal cost $c$. Then, we will apply this optimal nuclear tax formula to the three situations (1), (2) and (3) mentioned in Section 3.5. For the sake of simplicity, the optimal nuclear tax formula will be limited to the case with inelastic demand $(\beta=0)$.

Optimal nuclear tax formula. If a nuclear firm with capacity constraint $q_{n, \text { max }}$ and constant marginal cost $c$, and a competitive fringe with linear marginal cost starting at $c_{0}$ with upward slope $\alpha$, operate in a 'dominant firmcompetitive fringe' market facing inelastic linear demand $q_{0}>q_{n, \max }$, in which nuclear technology is viable $\left(c<c_{0}+\alpha q_{0}\right)$ then $\tilde{\tau}$ is an optimal choice of the nuclear tax rate for a government that maximizes welfare including a fraction $\sigma$ of corporate profits:

$\tilde{\tau}=\max \left\{c_{0}-c+\alpha\left(q_{0}-2 q_{n, \max }\right), \frac{(2-3 \sigma)\left(c_{0}-c\right)-\alpha q_{0} \sigma}{4-3 \sigma}\right\}$.

If the first term prevails in the maximization, then no withholding of nuclear capacity takes places. If the second term prevails, then there is withholding.

Proof. The government's optimization problem is to choose a tax rate $\tau$ to maximize $W$ from Eq. (8), subject to the strategic behavior of the nuclear firm, which can be expressed as:

$q_{n}=\min \left\{q_{n, \max }, \frac{\alpha q_{0}+c_{0}-c-\tau}{2 \alpha}\right\}$

Note that Eq. (10) is essentially the same expression as Eq. (6) with $c_{n}$ replaced by the applicable nuclear $\operatorname{cost} c$ plus the $\operatorname{tax} \tau$, and with explicit application of the constraint $q_{n \text { max }}$ on nuclear capacity. The first term in the minimization in Eq. (10) refers to a case in which the capacity constraint is binding; the second term refers to a case in which there is withholding.

For sufficiently low (and potentially negative) $\tau$, the second term $\left(\alpha q_{0}+c_{0}-c-\tau\right) / 2 \alpha$ in Eq. (10) can be made arbitrarily large. Hence, for sufficiently low $\tau, q_{n}$ is set by the first term in the minimization: $q_{n, \max }$. For larger $\tau$, the second term will diminish, to the point where it drops to $q_{n \text {,max }}$. This happens when $\tau=\tau_{\text {lim }}$ :

$\tau_{\text {lim }}=c_{0}-c+\alpha\left(q_{0}-2 q_{n, \max }\right)$.

For $\tau>\tau_{\text {lim }}$, nuclear output $q_{n}$ is set by the second term. To summarize, $q_{n}$ from Eq. (10) can be rewritten as:

$q_{n}= \begin{cases}q_{n, \max }, & \tau \leq \tau_{\text {lim }} \\ \frac{\alpha q_{0}+c_{0}-c-\tau}{2 \alpha}, & \tau>\tau_{\text {lim }} .\end{cases}$
We now derive the shape of $W$ as a function of $\tau$ in order to find the government's optimal tax rate:

- For $\tau \leq \tau_{\text {lim }}, q_{n}$ is constant at $q_{n, \max }$, hence the market equilibrium is not affected by a change in $\tau$, so that $d C S / d \tau=0$ and $d \pi_{f} / d \tau=0$. Furthermore, $d G / d \tau=q_{n \text { max }}$ and $d \pi_{n} / d \tau=-q_{n \text {,max }}$. As a result, we find that for $\tau \leq \tau_{\lim }, d W / d \tau=(1-\sigma) q_{n \text { max }}$. Since $\sigma \leq 1$ (i.e., the fraction of national shareholders can obviously not exceed $100 \%$ ), no value of $W$ in the range $\tau<\tau_{\text {lim }}$ is higher than the value for $\tau=\tau_{\text {lim }}$.

- For $\tau>\tau_{\text {lim }}$ there is withholding. The equilibrium price can be easily derived from Eqs. (4) and (12):

$p_{w h}^{*}=\frac{1}{2}\left(c+\tau+c_{0}+\alpha q_{0}\right)$

from which CS can be derived. Using also $G=\tau q_{n}$, one can derive an analytical expression for the government's objective function $W_{w h}$ in case of withholding, which is a concave quadratic function of $\tau$. The government's overall objective function $W$ coincides with $W_{w h}$ in the range of $\tau$ where withholding takes places, i.e. for all $\tau>\tau_{\text {lim }}$. The maximum value of $W_{w h}$ is reached for:

$\tau_{\text {peak }}=\frac{(2-3 \sigma)\left(c_{0}-c\right)-\alpha q_{0} \sigma}{4-3 \sigma}$

There are two possible cases: $\tau_{\text {peak }} \leq \tau_{\text {lim }}$ and $\tau_{\text {peak }}>\tau_{\text {lim }}$ :

Case 1. $\tau_{\text {peak }} \leq \tau_{\text {lim }}$. In this case, $\tau_{\text {peak }}$ is below the range of $\tau$ for which withholding takes places. Hence, $W$ must be declining in $\tau$ in the entire range where withholding takes place (i.e., for all $\tau>\tau_{\text {lim }}$ ). Since, in addition, no $\tau$ below $\tau_{\text {lim }}$ leads to a higher value of $W$ than $\tau_{\text {lim }}$ and $W$ is continuous at $\tau=\tau_{\text {lim }}$, we find that $\tilde{\tau}=\tau_{\text {lim }}$ is an optimal tax rate in this case.

Case 2. $\tau_{\text {peak }}>\tau_{\text {lim. }}$. In this case, $\tau_{\text {peak }}$ is in the range of $\tau$ for which withholding takes place. Hence, for $\tau>\tau_{\text {lim }}$, we find that $W$ reaches a maximum for $\tau=\tau_{\text {peak }}$. Since no $\tau$ below $\tau_{\text {lim }}$ leads to a higher value of $W$ than $\tau_{\text {lim }}$ and $W$ is continuous at $\tau=\tau_{\text {lim }}$, the optimal tax rate in this case is $\tilde{\tau}=\tau_{\text {peak }}$.

Putting both cases together, we find Eq. (9).

For $\sigma=1$, the optimal nuclear tax formula simplifies to

$\tilde{\tau}=\max \left\{c_{0}-c+\alpha\left(q_{0}-2 q_{n, \max }\right), c-\left(c_{0}+\alpha q_{0}\right)\right\}$

in which the first term is larger than the second term if $q_{n, \max } \leq q_{0}+\left(c_{0}-c\right) / \alpha$. In the short run, when the relevant cost $c$ is just $c_{n}$, this condition is satisfied by a large margin because of assumption (7). Even in the long run, for typical parameter values, the condition is satisfied. ${ }^{8}$ Hence, when $\sigma=1$, we find that the first term in the maximization typically prevails: $\tilde{\tau}=c_{0}-c+\alpha\left(q_{0}-2 q_{n, \max }\right)$. The intuition is that $\sigma=1$ represents a government that cares about overall efficiency, hence it would not set a tax that would push the nuclear firm into inefficient withholding behavior. In fact, $\tilde{\tau}$ may be negative when $c$ is sufficiently large (e.g. when investments are considered) or when the potential $q_{n \text {,max }}$ is large: the government gives a subsidy for nuclear power in order to make sure that the full potential $q_{n \text {,max }}$ is realized. Such cases with large $c$ or $q_{n, \max }$ make the capacity constraint less relevant, and hence-in line with Romano (1988) and Train (1991)-the optimal policy is a subsidy.

For $\sigma=0$, the optimal nuclear tax formula simplifies to:

$\tilde{\tau}=\max \left\{c_{0}-c+\alpha\left(q_{0}-2 q_{n, \max }\right), \frac{c_{0}-c}{2}\right\}$

${ }^{8}$ Note that the second term is the nuclear cost minus the marginal cost of the fringe if all demand were supplied by the fringe. The latter is usually very high, thereby making the second term large and negative. 
in which the first term is larger than the second if $2 q_{n, \max } \leq q_{0}+$ $\left(c_{0}-c\right) / 2 \alpha$. Hence, the first term prevails when the maximum nuclear generation is small compared to total demand and/or the cost advantage of nuclear power is large (e.g. in the short run, when investments are not considered). In such cases, there is a large margin for the government to impose taxes without causing any withholding, so even a government that does not care about profits may end up in a situation in which the capacity constraint is still binding for the nuclear firm. Note that even a government with $\sigma=0$ may choose to set a negative tax, i.e. a subsidy. This would never happen in the short run since the short-run marginal cost $c_{n}<c_{0}$, which would automatically make $\tilde{\tau}$ positive due to the second term in the maximization. In the long run however, $\tilde{\tau}$ may be negative if and when the benefits of lower consumer prices outweigh the subsidy costs.

We now apply the optimal nuclear tax formula to the three situations mentioned in Section 3.5: short run, long run, and medium run.

\subsection{Short-run taxation potential}

Let us consider the introduction of an unexpected tax on nuclear production, as it happened in the case of Belgium. 'Unexpected' means that the tax was not anticipated at the time of investment in nuclear capacity. Hence, this is the short-run case, and the only relevant costs are the short-run marginal costs $c_{n}$. We can derive the optimal short-run tax $\tilde{\tau}_{s r}$ by substituting $c=c_{n}$ in the optimal nuclear tax formula (9). The effect is illustrated in Fig. 2. For the nuclear firm, a tax $\tau$ increases the short-run marginal cost of production from $c_{n}$ to $c_{n}+\tau$. As a result, the intersection point of $M R_{n}$ and $M C_{n}$ moves to point $C$. If $\tau$ is high enough, the intersection point may move further up the $M R_{n}$ curve, the constraint $q_{n} \leq q_{n, \max }$ may no longer be binding and the nuclear firm would withhold some of its capacity. The case illustrated in Fig. 2 is a case in which the parameters are such that the optimal tax rate $\tilde{\tau}_{s r}$ causes no withholding. The first term in the maximization in Eq. (9) prevails:

$\tilde{\tau}_{s r}=c_{0}-c_{n}+\alpha\left(q_{0}-2 q_{n, \max }\right)$.

One can show that with the calibration parameters of Section 7 the first term prevails (and hence Eq. (17) is valid) when the maximum nuclear capacity represents less than $60 \%$ of total demand. Among the countries in Table 1, only France has a higher share of nuclear generation.

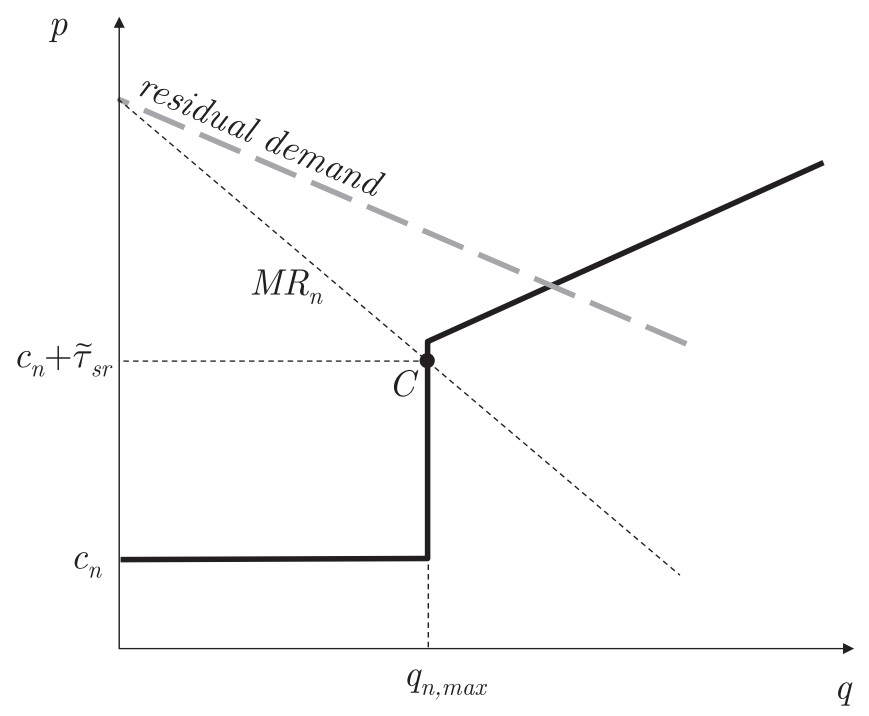

Fig. 2. Short-run impact of an unexpected tax on nuclear production.
The short-run tax result (17) demonstrates that it is possible (and optimal in the short run) for governments to impose a substantial ${ }^{9}$ unexpected tax on nuclear production, without even affecting the equilibrium on the electricity market. An immediate side-effect of such a tax is that incentives for efficiency improvements at nuclear power plants vanish. Indeed, according to Eq. (17) any investment that reduces $c_{n}$ would lead to an increase of $\tilde{\tau}_{s r}$ by the same amount, leading eventually to the same total costs for the nuclear firm. The situation of the nuclear firm becomes similar to the situation of a regulated firm under cost-of-service regulation. Fabrizio et al. (2007) analyze efficiency improvements induced by a transition from cost-of-service regulation to market-oriented environments for a large set of US electric generating plants. Their estimates suggest that investor-owned utility plants in restructuring regimes reduced their labor and non-fuel operating expenses by $3 \%$ to $5 \%$ in anticipation of increased competition in electricity generation, relative to plants in states that did not restructure their markets. The reverse effects might be expected in the taxation case analyzed in this paper. In addition to this immediate impact, the tax may have an adverse effect on long-run reinvestment incentives. This will be studied in Section 5 .

\subsection{Credible commitment to the optimal long-run tax rate}

The previous section studied the optimal tax rate that a government can set in the short run. However, the optimal tax rate will be different when the long run is considered, i.e. when capacity of the nuclear firm is not yet fixed and needs to be decided upon. Practically, this corresponds to the situation that arises when the current nuclear capacity is decommissioned and the nuclear firm makes its reinvestment decision, taking into account a tax rate set by the government. Let us assume that the government chooses a tax rate before the nuclear firm's reinvestment decision, and that the government can make a credible commitment to maintain this tax rate after the capacity has been built.

We can derive the government's optimal choice of the tax rate from the optimal nuclear tax formula (9) by replacing $c$ with $c_{n}+f_{n}$ (recall that $f_{n}$ is the annuity of investment costs plus any relevant fixed operating costs, per unit of nuclear capacity). The formula is easiest to interpret when we assume $\sigma=0$, i.e. the power generation sector has no national shareholders, or the government does not care about them. Then we find the following optimal long-run nuclear tax rate:

$\tilde{\tau}_{l r}=\max \left\{\tilde{\tau}_{s r}-f_{n}, \frac{c_{0}-c_{n}-f_{n}}{2}\right\}$

in which $\tilde{\tau}_{s r}$ refers to the expression from Eq. (17). It is clear that for sufficiently large $f_{n}$ (as is the case in the simulation in Section 7), the second term in Eq. (18) prevails. With $\sigma=0$ the second term simplifies to a situation in which the government takes $50 \%$ of the nuclear firm's cost advantage, i.e. the distance between nuclear costs and the next cheapest technology.

On the other hand, when $\sigma=1$, the optimal nuclear tax formula yields:

$\tilde{\tau}_{l r}=\max \left\{\tilde{\tau}_{s r}-f_{n}, c_{n}+f_{n}-\left(c_{0}+\alpha q_{0}\right)\right\}$

in which the first term usually prevails, because the second term is depressed by the component $c_{0}+\alpha q_{0}$, which is usually quite large because it represents the marginal cost if all demand is supplied by the fringe. The resulting tax or subsidy is then simply the short-run value $\tilde{\tau}_{s r}$, adjusted by $f_{n}$.

It is easy to see that $\tilde{\tau}_{l r}<\tilde{\tau}_{s r}$, and that the difference becomes larger when $f_{n}$ is larger. In fact, $\tilde{\tau}_{l r}$ according to Eq. (18) is not necessarily positive. In general, large $f_{n}$ will make $\tilde{\tau}_{l r}$ small or negative. The government therefore faces a trade-off: on the one hand, short-run welfare maximization would require taxing current nuclear capacity at a rate $\tilde{\tau}_{s r}$, but

\footnotetext{
${ }^{9}$ An indication of the likely size of such a tax is provided in Section 7.
} 
this would harm government credibility, thereby hampering reinvestment (as will be discussed in Section 5). On the other hand, the optimal long-run tax rate $\tilde{\tau}_{l r}$ in this setting is rather low. If, in order to preserve its credibility, the government decides to apply $\tilde{\tau}_{l r}$ also to current capacity (instead of applying $\tilde{\tau}_{s r}$ ), this would leave a very large part of current short-run nuclear rents untouched. Ideally, the government would be able to make a credible commitment to distinguish its tax rate on current capacity from its tax rate on new capacity, but this may be difficult to do.

\subsection{The medium run: Lifetime extension agreements}

Belgium's government first decided to extend the lifetime of the country's nuclear power plants. Only later, it imposed a contested tax on nuclear producers. An alternative is the German approach, in which a tax was agreed between government and the nuclear firms in return for a lifetime extension. ${ }^{10}$ The latter option is arguably preferable from the perspective of government credibility and investment incentives.

We can analyze such a lifetime extension agreement using the reasoning of Section 4.2. Indeed, lifetime extension is very similar to reinvestment, but the reinvestment $\operatorname{cost} f_{n}$ is replaced by a significantly lower refurbishment cost $f_{n}^{\prime}$. We simplify the bargaining process between the government and the nuclear industry by assuming a Stackelberg structure in which the government credibly commits to a tax rate $\tau$ in the first stage, and a dominant nuclear firm responds in a second stage by deciding on how much of the nuclear capacity will have its lifetime extended. The optimal tax to be set in return for a lifetime extension can then be derived again from the optimal nuclear tax formula (9). For the sake of simplicity, we assume $\sigma=0$ (no national shareholders, or the government does not care about them), so that the optimal tax is the same as in Eq. (18) with $f_{n}$ replaced by $f_{n}^{\prime}$. This can be conveniently analyzed graphically, as in Fig. 3, where $\left(c_{0}-c_{n}-f_{n}^{\prime}\right) / 2<\tilde{\tau}_{s r}-f_{n}^{\prime}$, hence the optimal medium-run nuclear tax rate $\tilde{\tau}_{m r}=\tilde{\tau}_{s r}-f_{n}^{\prime}$.

Because the cost $f_{n}^{\prime}$ of refurbishing an existing plant is much lower than the $\operatorname{cost} f_{n}$ of building a new plant, the agreed $\operatorname{tax} \tau$ allows the government to capture at least a sizeable part of the nuclear lifetime extension rent $\left(p_{0}^{*}-c_{n}-f_{n}^{\prime}\right) q_{n, \max }$. The part captured by the government is indicated in light shading in Fig. 3. However, a large part of the rent-shown in dark shading in Fig. 3-cannot be captured through a lifetime extension and taxation agreement with a single dominant nuclear firm. The reason is that a further increase of the tax rate would trigger a reduction of the amount of capacity of which the lifetime is extended, and therefore lead to lower tax revenues. By introducing competition for lifetime extension licenses, a larger share of the rent can be captured. This policy alternative will be discussed in Section 6.2.

\section{Impact of lack of government commitment on investment decisions}

The government's ability and incentives to introduce ex-post taxes on nuclear production in the short run, as in Section 4.1, may hamper investments in new nuclear capacity-or any other generating capacity with high capital costs-because firms may fear expropriation of profits. As mentioned in the literature review: a solution as analyzed by Janeba (2000), in which firms with low capital costs build excess capacity distributed across multiple jurisdictions in order to shift production depending on ex-post taxation, cannot work in our setting due to cost reasons, while constitutional or reputational commitment strategies are often unrealistic. In conclusion, credible commitments not to raise the tax ex post are difficult. The remainder of this section therefore considers cases of non-credibility, with different levels of commitment.

\footnotetext{
10 The lifetime extension was later revoked in the aftermath of the Fukushima accident which is, in fact, an illustration of ineffective government commitment, which will be the subject of Section 5 .
}

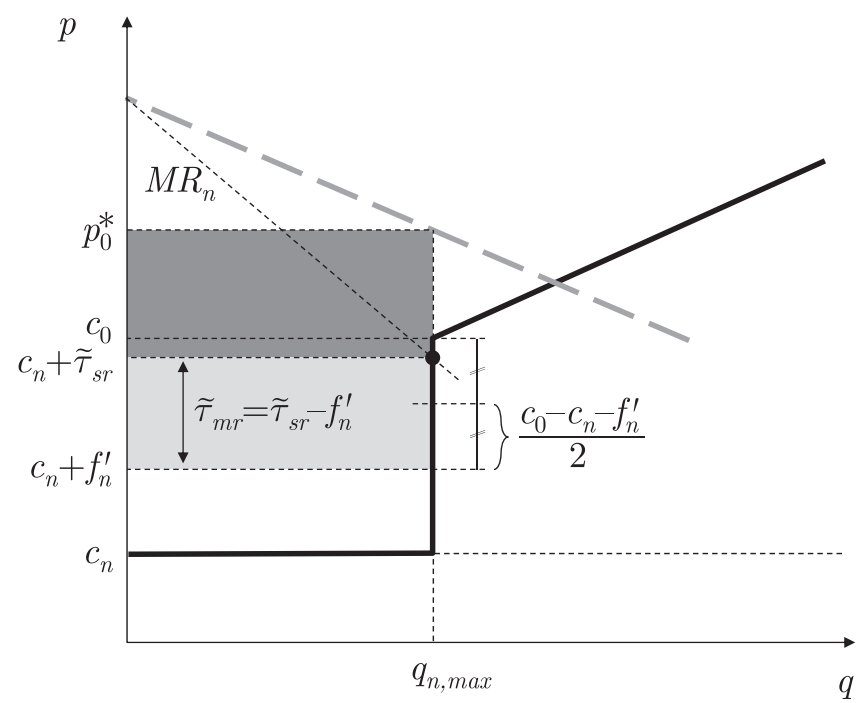

Fig. 3. Taxation in return for lifetime extension.

Unsurprisingly, we will find that non-credibility is detrimental for investment incentives. Armstrong and Sappington (2006) in their review of regulated industries argue that "if regulators are to design and implement policies that best serve the long-term interests of consumers they must be able to develop policy credibility by resisting short-term pressures to renege on long-term promises." The required regulatory commitment powers can be enhanced by a strong legal system, long tenure and a clear mission statement. On the other hand, if regulatory capture is likely-i.e. when the regulator is likely to generally implement policies that further the interests of particular groups-it may be best to restrict the powers of the regulator.

Section 5.1 first analyzes the effects of the optimal short-run tax $\tilde{\tau}_{s r}$ (from Eq. (17)) on investment incentives, when this tax is made permanent and the government is able to commit to it. Section 5.2 investigates a situation in which the government cannot make any credible commitment at all, or when there is a non-zero probability that it cannot.

\subsection{Credible commitment to the short-run tax rate}

Suppose the government imposes a tax $\tilde{\tau}_{s r}$ on current nuclear power production, according to Eq. (17). When the current nuclear capacity expires and needs to be replaced, nuclear firms will take the tax $\tilde{\tau}_{s r}$ into account when making the reinvestment decision. This would be the case for example, if the Belgian government reverses its phase-out policy and invites the incumbent to invest in a new nuclear power plant to replace an old plant: the investor may fear expropriation and demand that the government abolish the nuclear tax or at least promise not to increase it. In this subsection we assume that the government can credibly commit to maintaining-i.e. not increasing- $\tilde{\tau}_{s r}$ after the replacement capacity has been built.

In their long-run reinvestment decision, firms will not only take into account the short-run marginal $\operatorname{cost} c_{n}$ and the tax $\tilde{\tau}_{s r}$ but also the fixed (investment) costs $f_{n}$ per unit of capacity built. The resulting reinvestment decision can be found by replacing $c_{n}$ with $c_{n}+\tilde{\tau}_{s r}+f_{n}$ in Eq. (6):

$q_{n, \text { reinv }}=\frac{1}{2}\left(q_{0}+\frac{c_{0}-\left(c_{n}+\tilde{\tau}_{s r}+f_{n}\right)}{\alpha}\right)$

in which we have assumed perfectly inelastic demand $(\beta=0)$ as in the setting of the optimal nuclear tax formula. Using Eq. (17) this can be simplified to:

$q_{n, \text { reinv }}=q_{n, \max }-\frac{f_{n}}{2 \alpha}$ 
which is obviously lower than the technical maximum $q_{n, \max }$. One can easily show that this reduction of nuclear capacity from $q_{n \text {,max }}$ to $q_{n, \text { reinv }}$ increases electricity prices by $f_{n} / 2$, i.e. the underinvestment in nuclear capacity due to the introduction of a tax according to Eq. (17), may lead to an increase in electricity prices equal to half the per-unit fixed (investment) cost.

\subsection{No credible commitment}

The caveat with Eq. (21) is that once the capacity $q_{n, \text { reinv }}$ has been installed, the government would be incentivized to increase the tax rate above $\tilde{\tau}_{s r}$. Ex post, the government could increase the tax to $\tilde{\tau}_{s r}+$ $f_{n}$ without causing any withholding of the capacity $q_{n, \text { reinv. }}$. In fact, by analogy with Eq. (17) it is easy to see that for any level of $q_{n, \text { reinv }}$ the government's optimal ex-post short-run tax $\tilde{\tau}_{s r}^{\prime}$ can be found by following the $M R_{n}$ curve:

$\tilde{\tau}_{s r}^{\prime}=M R_{n}-c_{n}$

A rational nuclear firm anticipates the government's ex-post tax increases. Hence, the long-run marginal cost curve $M C_{n, l r}$ changes to include the ex-post tax increase:

$M C_{n, l r}=c_{n}+f_{n}+\tilde{\tau}_{s r}^{\prime}=f_{n}+M R_{n}$.

For $f_{n}>0$ (i.e., the obviously realistic case of positive investment cost) the lines $M C_{n, l}$ and $M R_{n}$ no longer intersect, hence no nuclear capacity is built if the government cannot make any credible commitment regarding the future tax rate.

Full loss of commitment power of the government is not required to create the conditions for underinvestment. Indeed, the possibility of the government changing tax rates ex-post, may be sufficient to deter investment. Suppose that there is a probability $\delta$ that the government makes an ex-post decision to apply the tax $\tilde{\tau}_{s r}^{\prime}$ according to Eq. (22). Conversely, with probability $(1-\delta)$, the government does not apply any tax. A risk-neutral firm will behave as if government imposed the expected value of the tax, i.e. the weighted average $\delta \tilde{\tau}_{s r}^{\prime}$. As $\delta$ increases, the expected tax increases, and reinvestment is reduced. One can show that $q_{n, \text { reinv }}$ becomes 0 when:

$\delta \geq 1-\frac{f_{n}}{c_{0}-c_{n}+\alpha q_{0}}$.

Hence, reinvestment may be completely deterred even if it is not certain that the government cannot commit to a tax rate.

\section{Policy discussion}

The previous section has highlighted the challenges of imposing an unexpected tax on a dominant nuclear firm. When it comes to policy discussions, there is a need to put the nuclear tax into the tax code of the country involved and this raises new questions. One can also abandon the tax solution and analyze a very different solution: the auctioning of the scarce nuclear capacity. We turn first to the tax code discussions and then go on to discuss the auctioning option.

\subsection{Other taxation instruments}

In this paper, the optimal nuclear energy tax has been derived for the case of an excise tax on nuclear production. This is a fixed amount per MWh of nuclear energy produced. Alternatively, the government could opt for an ad valorem tax, a profit tax, or a lump sum tax. The former two taxes are in fact similar in structure to the excise tax we have considered so far. In theory, in the case of a pure monopoly, an ad valorem tax-proportional to the nuclear firm's revenues-yields a larger nuclear output for the same tax revenue than an excise tax. ${ }^{11}$ In our case however, the difference will be small due to the presence of the competitive fringe, which makes residual demand fairly elastic. A special profit tax-proportional to the nuclear firm's profits-circumvents the problem of withholding, since the nuclear firm's incentives remain unaltered. In principle it also alleviates the reinvestment problem: if investment costs are correctly accounted for in the firm's profits, they reduce the tax on the profits of the new plants. However, the nuclear firm may still fear expropriation: a government that has created a track record of changing rules during the game (i.e. when it imposed the special profit tax) may be expected to change the rules again when new investments are completed. Moreover, the special nuclear profit tax may be difficult to implement: firms could attempt to evade the nuclear profit tax by inflating costs, shifting costs between nonnuclear and nuclear plants, or overstating the allocation of overhead costs to nuclear subsidiaries. ${ }^{12}$ From a legal perspective, it may be challenging to tax the same profit twice, i.e. both through regular corporate taxation and through the special nuclear profit tax. In any case, the profit tax bears some resemblance to the excise tax, because also the optimal excise tax depends on the difference between the price of the fossil fuel alternative (via $c_{0}$ ) and the marginal cost of nuclear power $\left(c_{n}\right)$. A pure lump sum tax, set independently of nuclear output, is a superior instrument compared to the excise tax. However, in many countries lump sum taxes would not be constitutional as they are not linked to a defined tax base. ${ }^{13}$

\subsection{Auctioning}

The main underlying reason why a large part of the medium-run nuclear rent cannot be captured in the setting of Fig. 3, is the fact that the nuclear firm is assumed to be a monopolist on the residual demand curve. One way to increase the share of rent captured by taxes-and thus increase welfare-is to introduce competition. More generally, as Armstrong and Sappington (2006) point out, competition can also play a particularly valuable role in the case of a weak regulator (inherently or intentionally). Armstrong and Sappington (2006) go on to review franchise bidding, i.e. competition for the right to serve as a monopoly supplier, as a way to introduce competition in situations in which pronounced scale economies render direct competition costly or impractical. The application to our case would be auctioning of licenses for either lifetime extension or reinvestment in new capacity. Here we will focus on lifetime extension, but analogous results can be obtained when the auctioning mechanism is applied to the reinvestment process.

We consider a situation in which the government opens up the lifetime extension licensing not only to the incumbent dominant firm but also to other players, in an auction. Suppose there are $k$ players, including the incumbent. For the sake of simplicity, we model the auctioning process as a Cournot game between nuclear firms. First the government sets a lifetime extension tax $\tau_{k}$, as in Section 4.3. Then, in Cournot competition, the $k$ players each decide on an amount of the capacity to be extended. In the previous sections, the reaction function of the dominant firm as a function of costs plus taxes, was always given by the marginal revenue curve $M R_{n}$, which, as is well-known, has twice the slope of the inverse residual demand curve. In a Cournot game the resulting total quantity of the $k$ players as a function of costs plus taxes (i.e. the

\footnotetext{
11 See e.g. Salanié (2003). A simple graphical analysis of a monopoly under ad-valorem versus excise taxation shows that the same tax revenue would lead to a lower quantity when an excise tax is applied as opposed to an ad valorem tax. The results become identical when the market becomes competitive or demand becomes fully elastic.

${ }^{12}$ As an illustration of this point: the size of the nuclear rent in Belgium was the subject of a fierce debate between the regulator, the nuclear incumbent and the central bank, see e.g. CREG (2011b).

${ }^{13}$ The use of lumpsum-type of taxes on nuclear output would violate several general principles of taxation law, in particular the principle of equality, see e.g. Vanistendaal (1996).
} 


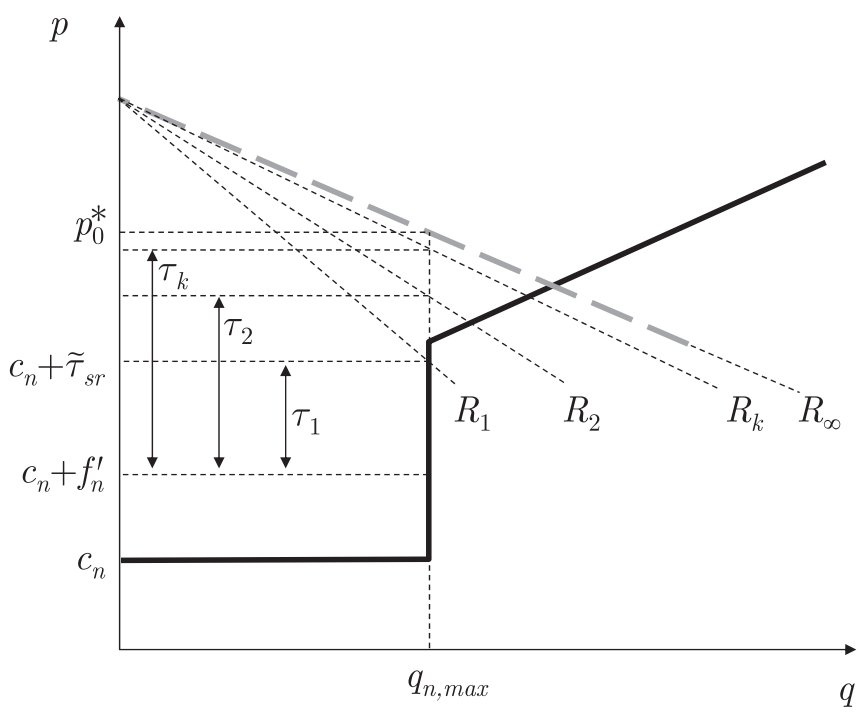

Fig. 4. Auctioning of lifetime extension licenses.

Table 2

Numerical values of parameters for the case of Belgium.

\begin{tabular}{lcl}
\hline Parameter & Value & Unit \\
\hline$q_{0}$ & 9422 & MW \\
$\beta$ & 0 & MW $\cdot$ MWh/EUR \\
$q_{n, \max }$ & 5345 & MW \\
$c_{n}$ & 20.1 & EUR/MWh \\
$f_{n}$ & 34.7 & EUR/MWh \\
$f_{n}^{\prime}$ & 6.9 & EUR/MWh \\
$c_{0}$ & 39.3 & EUR/MWh \\
$\alpha$ & 0.0053 & EUR/MWh/MW \\
\hline
\end{tabular}

aggregate reaction function $R_{k}$ ) is a similar line, but with a slope of $(k+1) / k$ times the slope of the inverse residual demand curve. This is shown in Fig. $4 .{ }^{14}$ The reasoning from Section 4.3 can now be applied almost identically. The optimal tax rate $\tau_{1}$ in the case of one dominant firm is the same as in Section 4.3. The optimal tax rates $\tau_{k}$ for $k>1$ become larger and larger, thereby allowing the government to capture an ever larger share of the nuclear rent. In the limit case of perfect competition $(k \rightarrow \infty)$ the tax becomes $\tau_{\infty}=p_{0}^{*}-c_{n}-f_{n}^{\prime}$ and the government captures the entire nuclear rent.

The auctioning approach was initially advocated by Demsetz (1968) but Williamson (1976) pointed out the difficulties associated to the asymmetric information. Indeed, the nuclear firm currently operating the power plant may have private information that is unavailable to other potential contenders in the auction. A firm may be reluctant to bid aggressively on a contract if it may win the contract not because it is the most capable producer but because it underestimates most severely the true (common) cost of operating the franchise. Armstrong and Sappington (2006) mention a number of other drawbacks that may lead to auctions with only one or a few participants, such as pronounced differences in skills between firms, or limited financial resources in some firms. Furthermore, if ownership changes as a result of the lifetime extension auction, the power plant may continue to be operated by the original owner, which could lead to principal-agent problems.

\footnotetext{
${ }^{14}$ As in Fig. 3, we assume $\left(c_{0}-c_{n}-f_{n}^{\prime}\right) / 2<\tilde{\tau}_{s r}-f_{n}^{\prime}$, hence $\tau_{1}=\tilde{\tau}_{s r}-f_{n}^{\prime}$.
}

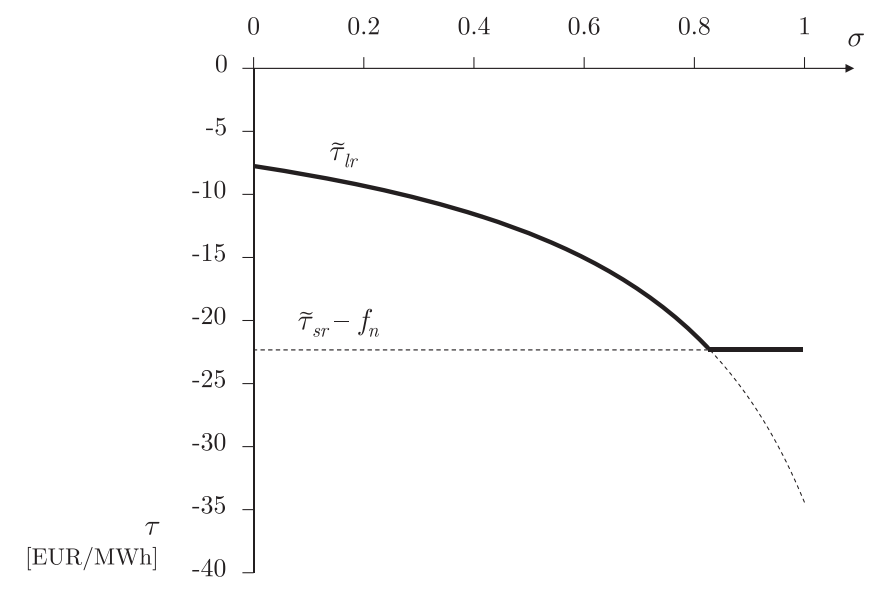

Fig. 5. Optimal long-run tax when the government can credibly commit, as a function of $\sigma$.

\section{Numerical simulations for the case of Belgium}

\subsection{Calibration and baseline}

In this section we illustrate the results from previous sections with a numerical simulation for the case of Belgium. Table 2 lists the calibration parameters. More information on how these values are obtained, can be found in Appendix A. Unless specified otherwise, we assume $\sigma=0$, i.e. there are no local shareholders of the power generation sector, or the government does not include their interests in its objective function. The choice for $\sigma=0$ can be justified by assuming that there is a well functioning international capital market, so that shares in domestic firms are distributed globally.

Since demand is assumed to be completely inelastic $(\beta=0)$, the equilibrium quantity in the absence of any intervention is obviously $q_{0}^{*}=9422 \mathrm{MW}$. The equilibrium price in the absence of any intervention is $p_{0}^{*}=60.9 \mathrm{EUR} / \mathrm{MWh}$. The total short-run rent obtained by the nuclear firm in this model is given by:

$\left(p_{0}^{*}-c_{n}\right) q_{n}=1910$ million EUR

which is in line with the estimate of 1.75 to 2.3 billion EUR made by the Belgian electricity regulator CREG (2011a). It should be emphasized that

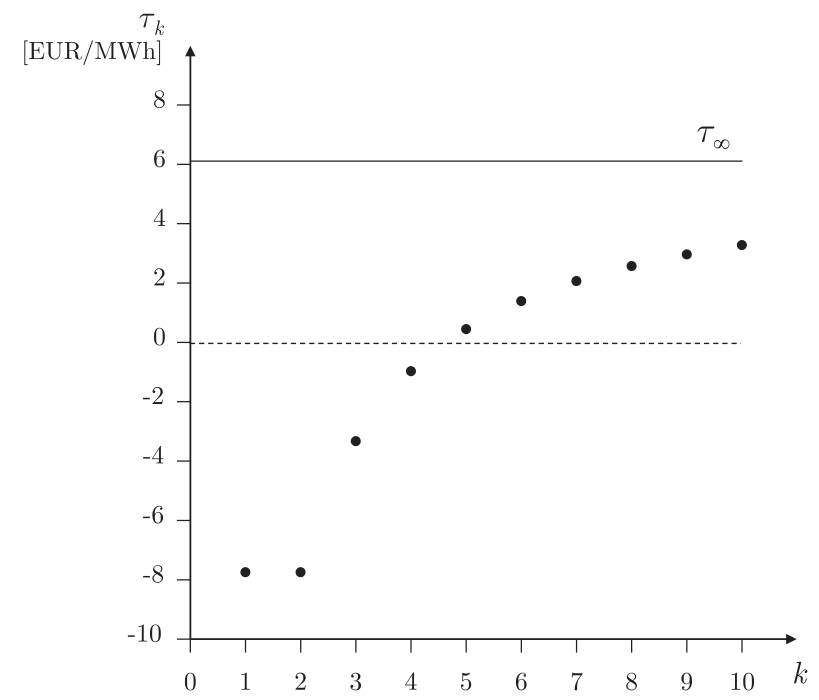

Fig. 6. Long-term tax on new nuclear investments as a function of the number of participants in the auction. 
Table 3

Summary of numerical results for $\sigma=0$

\begin{tabular}{|c|c|c|c|}
\hline Topic & Scenario & $\begin{array}{l}\text { Tax } \\
\text { (EUR/MWh) }\end{array}$ & Comment \\
\hline \multirow{3}{*}{$\begin{array}{l}\text { Taxation of a monopolist with a capacity constraint } \\
\text { by a government that can commit* }\end{array}$} & Short run: Optimal unanticipated tax & $12.5^{* *}$ & $31 \%$ of rent captured \\
\hline & $\begin{array}{l}\text { Long run: Optimal tax on new investments, with one nuclear } \\
\text { firm }\end{array}$ & -7.8 & Subsidy to avoid withholding \\
\hline & $\begin{array}{l}\text { Medium run: Optimal tax on lifetime extension of old nuclear } \\
\text { power plants, negotiated with incumbent only }\end{array}$ & 6.2 & $18 \%$ of rent captured \\
\hline \multirow[t]{3}{*}{ Auctioning } & Auctioning of lifetime extension licenses with 3 players & 24.5 & $72 \%$ of rent captured \\
\hline & Perfect competition for lifetime extension licenses & 33.9 & Complete rent capture by government \\
\hline & Perfect competition for nuclear licenses for new investments & 6.1 & Complete rent capture by government \\
\hline
\end{tabular}

* If the government cannot credibly commit, or there is more than $50 \%$ chance of an ex-post short-run tax, then there is no more investment in new nuclear capacity.

** If this tax is made permanent and applied to new investments as well, there would be $1 / 3$ less investment than without the tax.

the estimation of the nuclear rent is not the objective of our model. Rather, the similarity with CREG (2011a) indicates that our numerical simulation is sensible.

7.2. Taxation of a monopolist with a capacity constraint by a government that can commit

\subsubsection{Short run (see Section 4.1)}

The unanticipated short-run tax according to Eq. (17) is:

$\tilde{\tau}_{s r}=12.5 \mathrm{EUR} / \mathrm{MWh}$

and the corresponding government revenues $G$ are 584 million EUR per year. This tax is much higher than the 5 EUR/MWh tax originally introduced by the Belgian government in 2008 , but it still captures only $31 \%$ of the total rent. It is remarkable to observe that the Belgian government subsequently increased its nuclear tax to $11 \mathrm{EUR} / \mathrm{MWh}$, which is much closer to the value computed here.

\subsubsection{Long run (see Section 4.2)}

Fig. 5 shows the optimal tax $\tilde{\tau}_{l r}$ for new investments as a function of $\sigma$, the share of local shareholders in the power generation sector. The optimal tax is the maximum of the two alternatives in the optimal tax formula (9). As expected, the optimal tax is negative, even when $\sigma$ is very low: it is optimal for the government to subsidize the construction of nuclear power, in order to prevent underinvestment. The subsidy is 7.8 EUR/MWh when $\sigma=0$, and increases with $\sigma$ up to a maximum of $22.2 \mathrm{EUR} / \mathrm{MWh}$ for $\sigma=0.82$, after which it remains constant because the maximum possible reinvestment $q_{n, \max }$ is reached.

\subsubsection{Medium run (see Section 4.3)}

As mentioned before, the problem is similar to the question of reinvestment (the 'long run'), but with a lower $\operatorname{cost} f_{n}^{\prime}$ instead of $f_{n}$. Applying Eq. (18) with $\sigma=0$ and with $f_{n}$ replaced by $f_{n}^{\prime}$ we find:

$\tilde{\tau}_{s r}-f_{n}^{\prime}=5.6 \mathrm{EUR} / \mathrm{MWh}$

$\frac{c_{0}-c_{n}-f_{n}^{\prime}}{2}=6.2 \mathrm{EUR} / \mathrm{MWh}$

hence the optimal tax is 6.2 EUR/MWh. The total potential (mediumrun) rent in this case is 1588 million EUR, which is less than the shortrun nuclear rent of 1910 million EUR mentioned earlier because of the lifetime extension cost $f_{n}^{\prime}$. With one player, the above-mentioned tax of $6.2 \mathrm{EUR} / \mathrm{MWh}$ captures only $18 \%$ of this rent.

\subsection{Impact of lack of government commitment on investment decisions}

As in Section 5, we now consider the effect of lack of government commitment. First, we study the case in which the government can credibly commit to the $12.5 \mathrm{EUR} / \mathrm{MWh}$ short-run tax rate computed above. In the longer run, if the $12.5 \mathrm{EUR} / \mathrm{MWh}$ tax is credibly maintained for new nuclear investment when current capacity has expired, then Eq. (21) indicates that only $39 \%$ of nuclear capacity will be replaced. This obviously depends on the assumption that there is only one nuclear firm that can decide to invest in Belgium. Note that in this dominant firm-competitive fringe model, with only one nuclear firm, the nuclear firm would not replace all nuclear capacity even if no nuclear tax is imposed. Indeed, even in the absence of any nuclear taxes, the dominant nuclear firm would only reinvest $61 \%$ of initial capacity. Still, the 12.5 EUR/MWh tax reduces reinvestment by more than a third. ${ }^{15}$

If no taxes are imposed on new nuclear capacity but there is a probability $\delta$ that the government will impose a short-run optimal tax ex-post, new nuclear investment may also be severely reduced, as explained in Section 5.2. According to Eq. (24), as soon as $\delta \geq 0.50$, there will be no more nuclear investment. In other words: in this dominant firm-competitive fringe model, a 1-in-2 chance of an ex-post nuclear tax, of which the level will be decided by the government after investment, is sufficient to deter all investment.

\subsection{Auctioning}

As discussed in Section 7.2, the optimal tax rate in a lifetime extension agreement (the medium run) with one player in this numerical setting, is 6.2 EUR/MWh. A higher tax would cause the nuclear firm to withhold too much capacity from the lifetime extension. As discussed in Section 6.2, government revenue can be increased by introducing competition, i.e. by auctioning the lifetime extension licenses. With more than one player, the government will set exactly the maximum tax rate that will make sure the lifetime of all capacity gets extended. As mentioned before, with one player, the tax captures only $18 \%$ of the rent. With more than one player, the taxation potential rapidly increases with $k$ : in an auction with three players, the government would set a tax of 24.5 EUR/MWh, capturing $72 \%$

\footnotetext{
15 An obvious question is then why the current capacity $q_{n, \max }$ has been built in the first place, given that a monopolist would build less capacity according to our model. One likely explanation is that the capacity was built during the time of regulated monopoly, in which the incumbent electricity firm would operate in a cost-plus scheme, and not on a free market as in our model.
} 
of the maximum rent potential. In a perfectly competitive setting, i.e. when $k \rightarrow \infty$, the government can capture the full rent with a tax of 33.9 EUR/MWh.

The same competition principle can be applied to the auctioning of new nuclear power plant licenses, if the government can credibly commit to an optimal long-run tax rate. The total potential rent is much smaller, because the investment cost for a new plant is much higher than the refurbishment cost. In this numerical simulation, the total long-run rent would be only 286 million EUR per year. However, a large number of players would be required in order for the government to capture a significant share of this rent, as shown in Fig. 6. For $k=1$ and $k=2$, we obviously find again the subsidy of 7.8 EUR/MWh shown earlier in Fig. 5. For higher $k$ the subsidy decreases, and becomes a tax when $k \geq 5$. In the fully competitive situation in which $k \rightarrow \infty$, the tax is $6.1 \mathrm{EUR} / \mathrm{MWh}$ and the entire rent is captured by the government.

The main numerical results are summarized in Table 3.

\section{Conclusions}

In this paper we have studied nuclear taxation using a stylized model of the electricity sector with one dominant nuclear producer and a competitive fringe of non-nuclear plants. In this section we summarize the main policy implications, focused on the case of a national government that is interested only in its budget and in consumer surplus and that does not care about power plant profits because they accrue to the international community of shareholders.

First, we find that the optimal nuclear tax is different for the short, medium and long run: in the short run the tax has the same order of magnitude as the nuclear taxes imposed in Belgium (after the 2012 increase) and Germany, while in the long run the tax is negative (i.e. a subsidy) if there is only one candidate for new investment. Second, the effect of a short-run tax depends on the credibility of government commitments. On the one hand, when a government has a reputation of honoring its commitments, it can tax an important part of inframarginal and scarcity rents in the short run without having to fear for refurbishment investments or investments in new plants. Such taxation could be justified when capital costs have already been fully refunded in a previously regulated market. On the other hand, when a government cannot credibly commit, even the possibility of a short-run tax could severely harm incentives for future investments in lifetime-extending refurbishment or new plants. Third, such commitment problems reveal the limits of the tax instrument. When there is natural scarcity in nuclear potential, other policies like inviting multiple competitive bidders for lifetime extension franchises or for investments in new plants, may be more efficient ways to increase government revenue.

Our stylized representation of the electricity market of a country with nuclear power could be further refined. In particular, it would be useful to enhance the integration of international imports in our model, as these may be quite important in the event of large underinvestment. Furthermore, since our analysis shows that multiparty negotiation of lifetime extension agreements and auctioning of new nuclear licenses seem to be the most attractive policies, further research on the details of such auctioning processes (following the work of Fridolfsson and Tangerås, 2011) would be beneficial.

\section{Acknowledgments}

The authors are grateful for the extensive comments of one referee, and would also like to thank the participants at the conference on "The Economics of Energy Markets" at Toulouse School of Economics in January 2010-in particular the discussant N. Ladoux-the ETE seminar in Leuven in March 2010, and the conference in honor of Yves Smeers at CORE-UCL in June 2010 as well as the members of the PhD committee of Joris Morbee. The usual disclaimers apply.

\section{Appendix A. Supplementary data}

Supplementary data to this article can be found online at http://dx. doi.org/10.1016/j.eneco.2015.06.007.

\section{References}

Armstrong, M., Sappington, D., 2006. Regulation, competition and liberalization. J. Econ. Lit. 44 (2), 325-366

Besley, T., 2006. Principled Agents? Oxford University Press, Oxford

Borenstein, S., Bushnell, J., Knittel, C.R., 1999. Market power in electricity markets: beyond concentration measures. Energy J. 20 (4), 65-88

BP, 2011. Statistical Review of World Energy 2011. BP plc, London.

Carlton, D., Perloff, J., 2000. Modern Industrial Organization. 3rd ed. Addison-Wesley, Reading, Massachusetts.

CREG - Commissie voor de Regulering van de Elektriciteit en het Gas/Commission de Régulation de l'Electricité et du Gaz, 2010a. Studie over de kostenstructuur van de elektriciteitsproductie door de nucleaire centrales in België. Studie (F)20100506CDC-968. CREG, Brussels.

CREG - Commissie voor de Regulering van de Elektriciteit en het Gas/Commission de Régulation de l'Electricité et du Gaz, 2010b. Studie over het nucleair akkoord in Duitsland en de toepassing ervan op België. Studie (F)101014-CDC-999. CREG, Brussels.

CREG - Commissie voor de Regulering van de Elektriciteit en het Gas/Commission de Régulation de l'Electricité et du Gaz, 2011a. Rente nucl'eaire : la CREG analyse les explications d'Electrabel et confirme sa position. CREG, Brussels (Press release, March 1 2011)

CREG - Commissie voor de Regulering van de Elektriciteit en het Gas/Commission de Régulation de l'Electricité et du Gaz, 2011b. La CREG confirme son estimation de la rente nucléaire et pointe les manquements du rapport de la Banque nationale. CREG, Brussels (Press release, May 4 2011)

De Tijd, 2010-2014. "Regering eist 250 miljoen van nucleaire sector", December 8 2010; "Regering geeft EDF cadeau van 12 miljoen euro bij berekening nucleaire rente", December 14 2012; "Electrabel vecht nucleaire 'monstertaks' aan”, June 152013. "Regering verlengt Doel 1 en 2 tot 2025", December 18 2014. Uitgeversbedrijf Tijd NV, Brussels.

Demsetz, H., 1968. Why regulate utilities? J. Law Econ. 11, 55-66.

E.ON, 2009. Financial Report 2009. E.ON AG, Düsseldorf.

Elia, 2011. Corporate website www.elia.be. Elia System Operator NV, Brussels (Last consulted on July 12th 2011).

European Commission, 2008. Energy Sources, Production Costs and Performance of Technologies for Power Generation, Heating and Transport. Commission Staff Working Document accompanying the Second Strategic Energy Review, An EU Energy Security and Solidarity Action Plan. SEC(2008) 2872 (Brussels).

Eurostat, 2011. Statistics downloaded from epp.eurostat.ec.europa.eu.

Fabrizio, K., Rose, N., Wolfram, C., 2007. Do markets reduce costs? Assessing the impact of regulatory restructuring on US electric generation efficiency. Am. Econ. Rev. 97 (4), $1250-1277$

Financial Times, 2011. “Germany plans nuclear extension”-September 7 2010. The Financial Times Ltd, London.

Fridolfsson, S., Tangerăs, T., 2011. Nuclear Capacity Auctions. IFN Working Paper No. 892.

Hobbs, B.F., Pang, J.S., 2007. Nash-Cournot equilibria in electric power markets with piecewise linear demand functions and joint constraints. Oper. Res. 55 (1), 113-127.

Janeba, E., 2000. Tax competition when governments lack commitment: excess capacity as a countervailing threat. Am. Econ. Rev. 90 (5), 1508-1519.

Matthes, F.C., 2010. Auswertungsaktualisierung des am 5. September 2010 ausgehandelten Modells für die Laufzeitverlängerung der deutschen Kernkraftwerke. Öko-Institut e.V, Berlin.

Newbery, D.M., 2002. European deregulation: problems of liberalising the electricity industry. Eur. Econ. Rev. 46, 919-927.

Platts, 2010. PowerVision database, version 2010. Platts (The McGraw-Hill Companies), New York.

Riordan, M., 1984. On delegating price authority to a regulated firm. RAND J. Econ. 15 (1), $108-115$

Romano, R.E., 1988. A monopolist should always be subsidized no matter how high the excess burden. Can. J. Econ. 21 (4), 871-873.

Salanié, B., 2003. The Economics of Taxation. The MIT Press, Cambridge, Massachusetts.

Stigler, G., 1971. The theory of economic regulation. Bell J. Bus. Econ. Manag. 2, 3-21.

The Economist, 2011. "German energy: nuclear? Nein, danke", June 2, 2011. The Economist Newspaper Limited, London.

Thuronyi, V. (Ed.), 1996. Tax Law Design and Drafting vol. 1. International Monetary Fund, Washington, D.C

Train, K., 1991. Optimal Regulation: The Economic Theory of Natural Monopoly. The MIT Press, Cambridge.

Vanistendaal, F., 1996. Legal Framework for Taxation, Chapter 2 in Thuronyi (1996) Downloadable from. http://www.ieo-imf.org/external/pubs/nft/1998/tlaw/eng/ch2.pdf.

Ventosa, M., Baillo, A., Ramos, A., Rivier, M., 2005. Electricity market modeling trends. Energy Policy 33, 897-913.

Wei, J.Y., Smeers, Y., 1999. Spatial oligopolistic electricity models with cournot generators and regulated transmission prices. Oper. Res. 47 (1), 102-112.

Willems, B., Rumiantseva, I., Weigt, H., 2009. Cournot versus supply functions: what does the data tell us? Energy Econ. 31, 38-47.

Williamson, O.E., 1976. Franchise bidding for natural monopolies-in general and with respect to CATV. Bell J. Econ. 7, 73-104. 